\title{
SOCIAL GEOLOCATION IN TOURISM - INTERRELATIONSHIP OF WEB 2.0 AND GEOGRAPHY
}

\author{
MARINOVIC, M[aja] \& ANDRLIC, B[erislav]
}

\begin{abstract}
For tourism subjects on the market to be utilized sustainably, the necessary infrastructures and enabling geographic environment and information on tourism which will attract tourists must be available. Enabling environment in this case refers to all the parameters required to make a complete tourist product. Information on the geographic existence of attractions sites and these infrastructures must be available to tourists and the general public this means that raw data on tourist sites and infrastructures has to be gathered, processed, structured, then stored and organized in such a way it is easily retrievable from storage. Research focus will be directed towards the usage of web 2.0 technological systems in tourist geography. Internet, as one of the most significant technological phenomena of our time, provides tourists completely new consumeropportunities, of which the most significant opportunity to provide immediate and always open access to social geolocation. Researches want to identify the practical role of location based services in developing tourism potentials in Croatia.

Keywords: tourism, geography, web 2.0, social neteworking, geolocation
\end{abstract}

\section{INTRODUCTION}

The modern tourism means a business activity which connects production and consumption in such a way that fully and with maximum profit meets the needs of guests that are usually referred to as tourism market demand. Companies nowadays deal with difficulties arising from challenges of growing e-markets and rapidly changing factor of customers' buying behaviour.

Changing economic conditions, new forms of consumer behaviour, and especially new technologies is likely to cause the emergence of new or growth of existing tourist market. In developed economies all the more attention is attached to the study of the role of new technologies in the field of hospitality and tourism. It is necessary to point out that technological progress is a key factor of modern world of tourism and geography. [10]

Based on empirical research, researchers want to provide analysis on the utilization of social geolocation potentials of tourism companies in eastern Croatia. This resarch will be first published analysis about social geolocation topic in eastern Croatia so it proves their importance. Limitation of the paper is fact that there is unsufficient level of geolocation usage among users in Croatia.

\section{THE TOURISM GEOGRAPHY SYSTEM}

In order to be able to understand the complex and dynamic nature of the contemporary tourism experience many tourism researchers utilize the concept of a tourism geography system. A system is an assemblage or interrelated combination of things or elements forming a unitary whole. [6] At its most basic, the tourism system consists of consumption and production and the experiences that are generated. In order to increase our understanding of tourism we are therefore also interested in identifying those elements and factors that contribute to tourism consumption and production. Given that movement is integral to tourism one way in which the tourism system can be understood is through the travel paths taken by individual consumers. This approach is usually termed a geographical system of tourism and consists of four basic elements as follows [5]:

- generating or source region - which is the permanent residence of the tourist and the place where the journey begins and ends.

- transit route - which is the path through the region across which the tourist must travel to reach his or her destination.

- destination region - the region which the tourist chooses to visit and which is a core element of tourism.

- environment - that surrounds the other three regions.

Other approach says that there are three major elements of the tourism geography system shown in Fig. 1:

- The Tourist Destination Region (where the tourists go to). The destination is the reason for tourism, it offers something different from what the tourist can experience at home. Destination types include coastal (sun and sea), urban (museums) and rural (wildlife or nature) destinations.

- The Traveller Generating Regions (where the tourists come from, their homes).

- The Transit Routes (the route of travel between the destination and his / her home and the different means of transport used to do this).

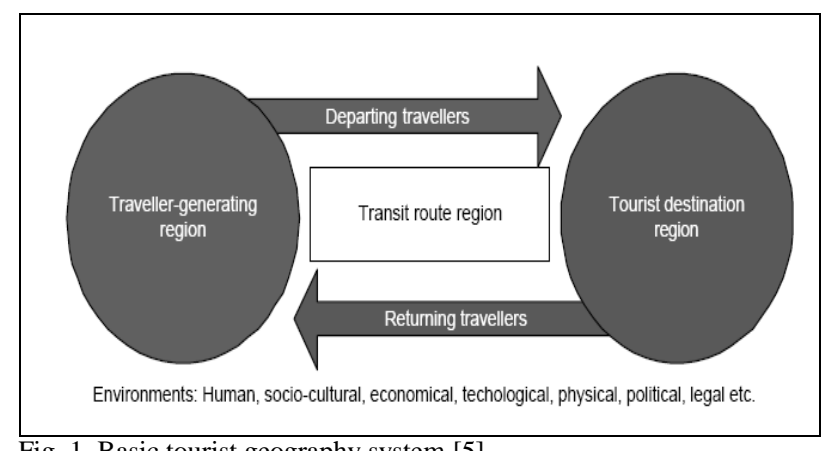

Fig. 1. Basic tourist geography system [5] 
There is a constant flow between the destination and the market - of tourists coming to the destination, of investment and expenditure in the destination, and of experiences and souvenirs out of the destination and back to the tourist generating region.

The geographical tourism system model is useful for identifying the flow of tourists from one location to another and the importance of connectivity between the generating region and the destination). Of course, there might bemore than one destination and therefore a whole system of destination regionsand transit route regions can exist for some tourists. Nevertheless, the basic form of the geographical tourism system is sufficient to illustrate a range of important dimensions of tourism [5]:

While the destination is the focal point of tourism activity, tourism will have affects over all elements of the tourism system. For example, while assessment of the economic and environmental affects of tourism can clearly be undertaken at the destination, a full assessment of impacts as a result of a tourist trip will need to include not only what happens at the destination but also in getting too and from that destination.

Destinations are accessible to tourism source regions. Such a statement may seem to be obvious yet its implications are profound. Different destinations will be variably accessible to source regions and vice versa. This means that some destinations will have natural advantages over others in relation to their accessibility and therefore potential market area. This is a factor that destinations will seek to exploit in competition with other destinations.

In relation to travel to the destination, different elements of the system will have different productive components even though they are used by the same consumer. The different elements that enable the production of tourism are identified. It is important to realize that it does not suggest that the elements that have been identified only occur in specific regions, rather it highlights the relative importance of various aspects of the tourism industry from the perspective of the consumer as they go from one stage of their trip to another, and hence from one part of the tourism system to another.

\section{THE TOURISM DESTINATION PLANNING AND MANAGEMENT}

The tourism sector includes all the business and organisations that are involved in providing the tourism 'experience'. The tourism experience comprises the five 'A's [1]:

1. Attractions (e.g. natural or cultural),

2. Activities (e.g. hiking or shopping),

3. Accommodation (e.g. hotels, guesthouses or camping sites),

4. Amenities (e.g. shops or restaurants)

5. Access (e.g. distance, suiTab. means of getting there such as flights, roads)

Destination planning needs to involve relevant stakeholders in a participatory way, to make sure that plans developed are relevant to both residents and tourists. Stakeholders that should be involved in planning include government, local communities, the private sector, non-governmental organizations (NGOs), research and education facilities, and development agencies.

Destination management includes marketing, quality of service andexperiences, visitor management, providing information and interpretation, infrastructure development, capacity development, funding, preserving and maintaining natural and cultural resources. Destination Management Organisations (DMOs) can be established to manage the different aspects of tourism within a destination and to guide collaboration between the different stakeholders.

There are many potential motivators that could relate buying factors in hospitality. Furthermore, there are a number of potential 'variations on a theme' for each individual motivator and they can be combined. No widely recognized way exists of categorizing the main motivating factors in hospitality. However, some of the major ones are outlined in Fig. 2.

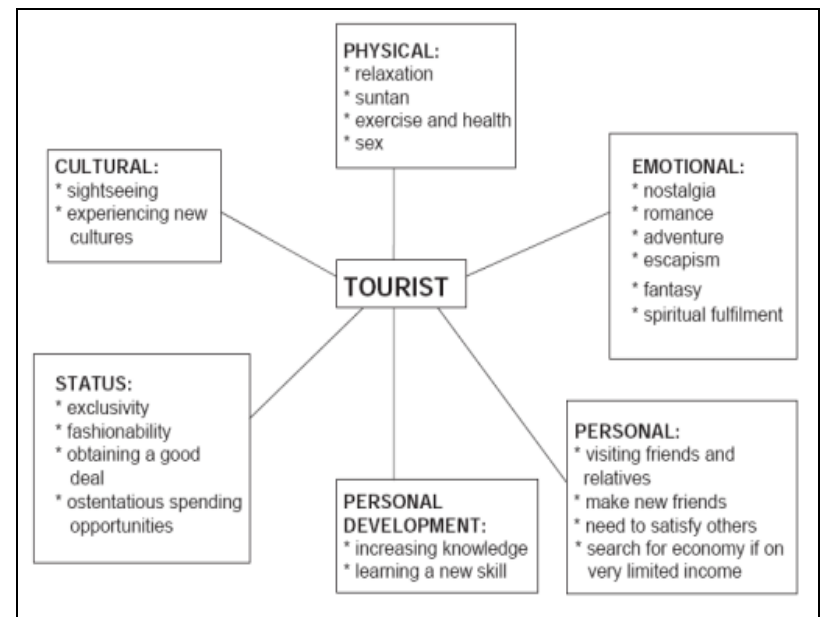

Fig. 2. A typology of motivators in tourism [8]

As this approach demonstrates, the market process in tourism starts long before the actual purchase and hasconsequences long afterward. In phases Internet is influencing on the tourist opinion about geographic destination. Precisely because of this the tourism pages have to be designed with careful researching of their target tourists and the way they will communicate to potential tourists. It is also important to find the right balance between the volume of information offered to visitors and the size and appearance of the tourist web page.

\section{GEOGRAPHIC MOBILE TARGETING}

Current authors who are investigating the web 2.0 marketing in the tourism industry ant its connection with geography are: Carvao, Coathup, Castañeda, Frías, Rodríguez, etc. This interrelationship of Internet and geography is very actual scientific area but there is unsufficient number of articles and researches of this theme in Croatia.

Different geographic regions have adopted and used the mobile channel at different rates, based on 
differences in the mobile network infrastructure, network speed, handset availability, laws, billing rates, and cultural norms. With mobile marketing, geographic segmentation is very much about the situation the customer's location might indicate. When people are in different geographic locations, they generally have different needs and different motivations.Mobile marketing campaigns will be more effective if you can anticipate with some precision where the recipients will be when they receive your marketing message.With location in mind, tourist can adapt message to suit the needs of your potential customer when at work, at home, in the car, when commuting on public transportation, while running errands, or while out for a night on the town. Understanding and anticipating customers' physical and geographic location also gives tourist companies insight into their physical surroundingsthey'll know whether it's noisy or crowded, whether they are near a computer, or even whether they're in a location where they might lose their cellphone signal, such as in a subway train. Different cities and regions have different norms of behaviour in geographic area.

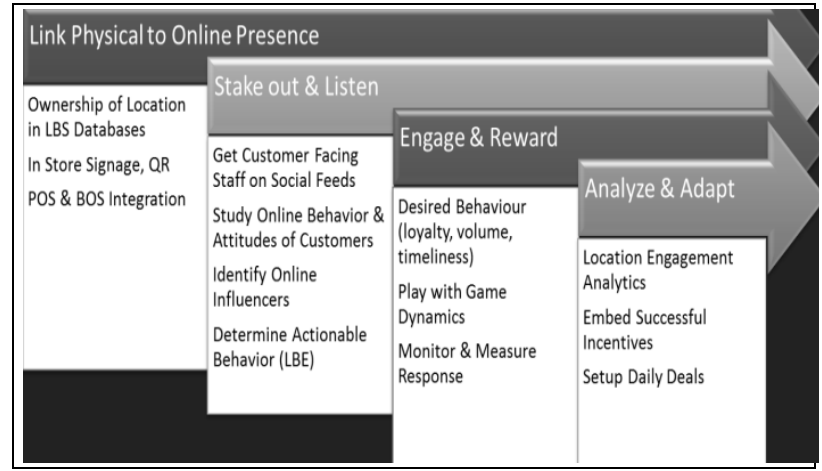

Fig. 3. Location based marketing model [8]

With the evolution and wide-spread use of smartphone devices, it was only a matter of time until location-based applications and services would start to be developed. By definition location-based media delivers content to a users mobile device depending on where they are located. It is a new way to deliver a targeted marketing message to users in a specific geographic location. [6].

\section{GEOGRAPHIC LOCATION BASED MOBILE APPLICATIONS}

In tourist geography and marketing, tracking and targeting are crucial to the success of market campaign. Although these are sometimes discussed separately, the intensely personal nature of the message and the heightened ability to track your customers' interaction demands that the two be considered together in mobile marketing. In the mobile world, targeting refers to both identifying key demographics and psychographics of your intended audience, and adapting marketing message to meet their needs. Tracking refers to any attempt to capture and evaluate data about the effectiveness of the mobile marketing campaign. The most important models are: Foursquare, Loopt, Brightkite and Yelp.
Foursquare is a free app that helps you and your friends make the most of where you are. When you're out and about, use foursquare to share and save the places you visit. And, when you're looking for inspiration for what to do next, we'll give you personalized recommendations and deals based on where you, your friends, and people with your tastes have been. Whether you're setting off on a trip around the world, coordinating a night out with friends, or trying to pick out the best dish at your local restaurant, foursquare is the perfect companion. Statistics about Foursquare are [9]:

- community: over 20 million people worldwide

- over 2 billion check-ins, with millions more every day

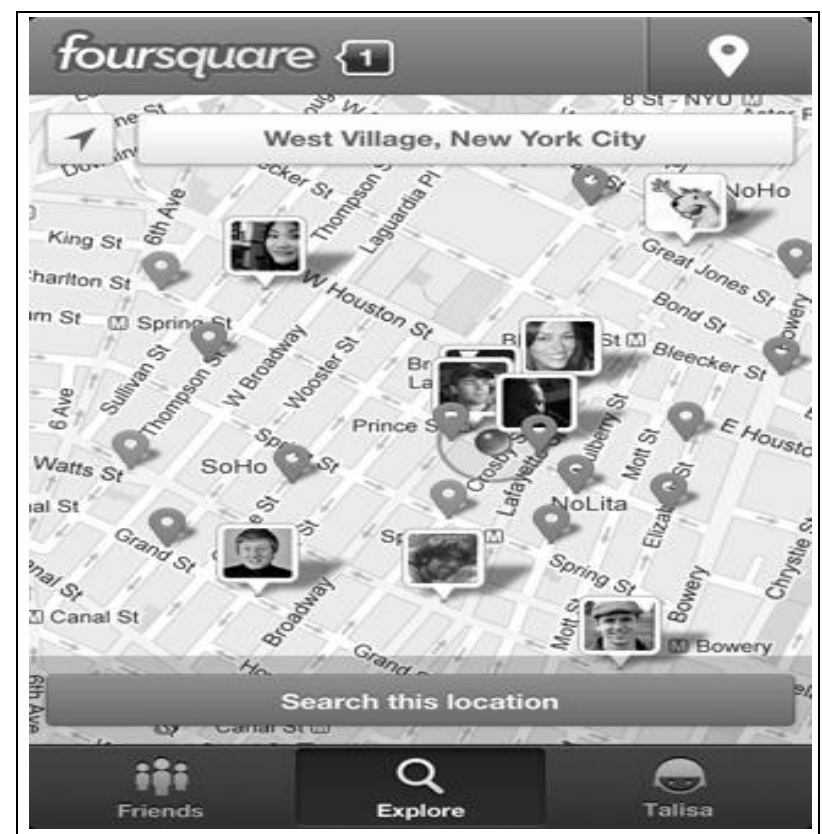

Fig. 4. Location based marketing mobile application Foursquare [13]

Loopt is a mobile social-mapping service that lets you use the location in your phone to discover the world around you. Find and enjoy the friends, places, and events around you right now. Using the mobile application tourists can [14]:

- ping friends to get updates on where they are

- discover local places and events

- check-In and share where you are with friends

- get coupons and exclusive deals from local retailers

Brightkite app lets tourists meet people around them, keep up with your friends, explore and discover new places. Become friends with people who go to the same places as you do, vote if you like or dislike recommendations/reviews, share with your other social networking sites, and control what you want your friends to be able to see.

Yelp has typically been known for its robust local directory with features like customer reviews, store information, and place recommendations. Now Yelp is getting into the location-based application business. They have added a check-in feature to the application that allows you to notify users where you are. Model helps share your location with friends, Twitter and Facebook. 


\section{METHODOLOGY AND RESEARCH RESULTS}

Primary authors research consisted of data collected via Internet in sample of tourism subjects in BrodPosavina, Pozega-Slavonia, Virovitica-Podravina, Vukovar-Srijem and Osijek-Baranja County. Scientific method was online survey. Disadvantage of method was certain tourist subjects are less likely to have internet access and to respond to online questionnaires. It is also harder to draw probability samples based on e-mail addresses or website visitations. Subjects were divided into four main groups: travel agencies, hotels and motels, doss houses, pensions and restaurants. Number of subjects from each county was $20(n=100)$. The aim of resarch was to identify number of check-ins, pictures, comments and friends on social profiles on Foursquare.

\begin{tabular}{|c|c|c|c|}
\hline & County & $\begin{array}{c}\text { Number of } \\
\text { comments }\end{array}$ & Pictures \\
\hline \hline 1. & Osijek-Baranja & 35 & 52 \\
\hline 2. & Brod- Posavina & 11 & 21 \\
\hline 3. & Virovitica-Podravina & 9 & 14 \\
\hline 4. & Vukovar-Srijem & 3 & 24 \\
\hline 5. & Pozega- Slavonia & 6 & 8 \\
\hline
\end{tabular}

Tab. 1. Comments and pictures statistics-author research

\begin{tabular}{|c|c|c|c|}
\hline & County & Friends & Visits \\
\hline 1. & Osijek-Baranja & 634 & 1627 \\
\hline 2. & Brod- Posavina & 194 & 739 \\
\hline 3. & Virovitica-Podravina & 88 & 346 \\
\hline 4. & Vukovar-Srijem & 111 & 203 \\
\hline 5. & Pozega- Slavonia & 74 & 124 \\
\hline
\end{tabular}

Tab. 2. Friends and visits statistics-authors research

At the end of this research can be concluded that the representation and recognition of social network Foursquare is relatively small when viewed all five counties studied as a whole. Still not equal representation in all counties, in others it is higher, while in others much less. If we look at the Osijek - Baranja County in her social network Foursquare is the most common recognize that it is up people in all segments. The reason for this is a tourist activity center, the size of the population, many young people who use social networks (university city). Somewhat lower prevalence of Foursquare in BrodPosavina County which is located on the second place of the study. Next in Virovitica County where the Foursquare recognized very few people. Almost equal recognition of social network Foursquare is in the last two counties that included research, such as VukovarSrijem and in Pozega - Slavonia county. In the last three counties only rarely used features of Foursquare because they are much smaller counties, underdeveloped, smaller population than in Osijek - Baranja county, not a tourist destination, and lower the younger population. But this will probably change in the future, because every day growing computer literacy and Internet development and will increase the use of social networks.

\section{CONCLUSION}

In conclusion, the literature and empirical research seems to suggest that Web 2.0 adoption amongst tourist businesses has been uneven and that they are failing to match consumer demand for the latest trends such as Web 2.0. There is general conclusion that technological systems, especially social geolocation is crucial to the future of tourist businesses on Croatian market, and can be used as technical innovation in marketing. However, there appears to be a host of barriers to social geolocation network uptake including limited resources and technical competence. It appears that adoption of social geolocation is influenced by a host of factors, including the size and type of the tourist subject and geographic location, but this will need to be determined through further researches on the sample of all tourist subjects in Croatia.

\section{REFERENCES}

[1] Baltadzhiev, S. \& Sofield, T. (2004) Training modules for community based tourism success in EPRP, International Trade Centre Export Led Poverty Reduction Program, UNCTAD/WTO, INT/W2/11

[2] Carvão, S.(2010). Embracing user generated content within destination management organizations to gain a competitive insight into visitors' profiles, Worldwide Hospitality and Tourism Themes, Vol. 2., No. 4, 2010

[3] Castañeda, J.A., Frías, D.M., Rodríguez, M.A.(2007). The influence of the Internet on destination satisfaction, Internet Research, Vol. 17., No. 4

[4] Cooper, C. \& Hall, M. (2008). Contemporary Tourism: An International Approach, Butterworth-Heinemann, Burlington

[5] Coathup, D. (1999). Dominant actors in international tourism, International Journal of Contemporary Hospitality Management, Vol. 11 No 2/3, 1999

[6] Hall, C.M. \& Page, S. (2006). The Geography of Tourism and Recreation: Space, Place and Environment, 3rd edn. London: Routledge

[7] Leiper, N. (1990) Tourism system, Massey University Department of Management Systems Occasional Paper 2, Auckland

[8] Swarbrooke, J. \& Horner, S. (1999) Consumer Behaviour in Tourism, Butterworth Heinemann, Oxford

[9] Pura, M. (2005) Linking perceived value and loyalty in locationbased mobile services, Managing Service Quality, Vol. 15 Iss: 6, pp. $509-538$

[10] Ruzic, D. \& Andrlic, B. (2009). Analysis of using Internet technology in hospitality marketing, Annals of DAAAM \& Proceedings

[11] http://www.searchenginejournal.com/location-based-marketingresources-and-tools/19683/ (2012). Accessed on: 2012-07-10

[12] http://plandigital.wordpress.com/2012/04/22/foursquare-specials/ (2012). Accessed on: 2012-07-12

[13] https://foursquare.com/about/new (2012) Accessed on: 2012-0712

[14] www.loopt.com/about/press/ (2012) Accessed on: 2012-07-12 